\title{
Multi-Product Economic Inventory Policy with Time Varying Power Demand, Shortages and Complete Backordering
}

\author{
Sandeep Kumar', Mukesh Kumar², Manoj Sahni, ${ }^{3}{ }^{\text {,* }}$ \\ ${ }^{1}$ Department of Mathematics, Graphic Era Hill University, Dehradun, Uttarakhand, India \\ ${ }^{2}$ Department of Mathematics, Graphic Era (Deemed to be University), Dehradun, Uttarakhand, India \\ ${ }^{3}$ Department of Mathematics, Pandit Deendayal Petroleum University, Gandhinagar, Gujarat, India
}

Received December 4, 2020; Revised January 30, 2021; Accepted February 24, 2021

\begin{abstract}
Cite This Paper in the following Citation Style
(a): [1] Sandeep Kumar, Mukesh Kumar, Manoj Sahni , "Multi-Product Economic Inventory Policy with Time Varying Power Demand, Shortages and Complete Backordering," Universal Journal of Accounting and Finance, Vol. 9, No. 1, pp. 98 - 104, 2021. DOI: 10.13189/ujaf.2021.090110.
\end{abstract}

(b): Sandeep Kumar, Mukesh Kumar, Manoj Sahni (2021). Multi-Product Economic Inventory Policy with Time Varying Power Demand, Shortages and Complete Backordering. Universal Journal of Accounting and Finance, 9(1), 98 - 104. DOI: 10.13189/ujaf.2021.090110.

Copyright $\bigcirc 2021$ by authors, all rights reserved. Authors agree that this article remains permanently open access under the terms of the Creative Commons Attribution License 4.0 International License

\begin{abstract}
The present article elaborates a multi-product economic inventory model in which multiple items are considered with demand, which depends on time, abides power law, shortages, and complete backordering. The rate of production is greater than the rate of demand for each item. This type of demand pattern is accessible to various kinds of practical problems in the present modern era. In this paper, the production rate is assumed to be directly proportional to the rate of demand. In real situations, demand is always dependent on the price of any product, so it is also assumed that demand is depleted linearly with the price. This paper aims to fulfill the requirement of products and maximize the overall profit in any organization. Optimal values of involved costs, price, re-order point, and scheduling period are also calculated. In this work, the objective is to maximize the total profit and optimize production quantity. Optimization methods are used to obtain the maximum profit. Shortages are permitted and completely backordered. Total cost and production quantity models for deteriorating items have been developed. The study is validated with a numerical example, and sensitive analysis of the optimal solutions concerning main parameters is carried out using the software Mathematica. The tables are also shown for optimal values of the present model.
\end{abstract}

Keywords Inventory, Power Demand, Lot Size,
Multi-Items, Shortages, Backordering

\section{Introduction}

In practical situations, customers' demand depends on time, and hence researchers presented some varying time models. Barbosa and Friedman [1] proposed a time-varying model for decaying items. Silver and Peterson [2] concludes that retail-level sales are proportional to displayed inventory, and more quantity of presented products will attract more customers to purchase. Mitra et al. [3] suggested a pattern of demand that varies with time. Baker and Urban [4] presented an EOQ model involving a demand pattern for a stock of power. After few years, Mandal and Phaujdar [5] studied a policy for decaying items with the demand which depends on stock. Sarkar et al. [6] presented a time and price-dependent production model in the environment of reliability and inflation. Urban [7] studied periods of an inventory model, unlike the demand of stock time by a given quantity. Alfares [8] presented a policy where the demand relates to the inventory level and cost of holding, which relates to the period of storage. Datta and Pal [9] studied a fixed demand inventory policy with 
inventory-level dependent demand for some fixed level and a non-variable rate of demand for the cycle (left) with an infinite time horizon. Lee and $\mathrm{Wu}$ [10] elaborated a policy optimal order quantity for decaying products with power demand and shortages. Singh et al. [11] introduced an EOQ model for decaying products with shortages and power pattern demand. Pal et al. [12] analyzed periods of an inventory distinct from the inventory demand by a known amount. Hwang and Hahn [13] introduced an inventory model of production for decaying items. Many researchers used holding cost always constant, but in some cases time- dependent holding cost is used. Singh and Mishra [14] introduced an EOQ scheme for perishable items with power pattern demand. Sicilia et al. [15] presented an optimum policy for lot size having demand of power pattern and production, which is directly proportional to demand rate.

Demand is always price dependent, so the price is one of the factors for any organization. Tripathi et al. [16] presented a system with a power pattern withholding cost and stock-related demand for two types of a business environment. Chaudhuri and Ray [17] introduced the money time value by studying an inventory policy with the stock-induced demand rate. Giri, Goswami, and Chaudhuri [18] studied a production model for perishable items with the influence of shortages. Banerjee and Sharma [19] studied an inventory policy with the price and time-dependent seasonal demand. Later again, Banerjee [20] introduced a combined economic lot-size system and supposed that lot-for-lot shipment scheme followed by the supplier with the retailer". In continuation, Goyal [21] analyzed Banerjee's policy by taking a batch having a number of same-shaped shipments, but the batch production had to be completed before the starting of shipment. Liu et al. [22] presented a joint investment policy for decaying products with quality and price-dependent demand. Hill [23] introduced an optimal lot-sizing inventory model of two-stage and inventory batching schemes. Zhu [24] introduced a dynamic replacement and production model by using random price-sensitive demand. Teng et al. [25] presented an increasing payment scheme. Goyal and Chang [26] introduced a model of ordering-transfer to obtain the retailer's optimal order amount and per order number of shifting from the warehouse. Yang and Wee [27] introduced an inventory policy of multi-lot-size production for decaying products. Heydari and Gholamian [28] presented a mixed integer probabilistic model by considering METRIC stochastic relation in a problem of location-routing. Hsieh et al. [29] presented the effect of shortages and delays in payment. Sarkar [30] presented sustainable ordering policies for non-instantaneous decaying products under carbon emission and multi-trade-credit-policies. Kumar et al. [31] in 2020 has developed a manufacturing reliability inventory model in which demand depends on advertising, time, and selling price.
In this study, we developed an inventory model based on demand pattern i.e., power demand, and it defines that type of demand, which varies with the rate of change in the form of a power function. This kind of demand pattern is used in situations of the high demand of products at the starting of the cycle or at the ending of the cycle.

\section{Notations and Assumptions}

\subsection{Notations}

In the present study the following notations are used:

$\mathrm{N}$ : Number of products in the system

T: Period of scheduling

$Q_{i}$ : Quantity of production for product $i$

$W_{i}$ : Quantity of demand for inventory cycle for product $i$

$d_{i}$ : Average demand for product $i$ and given as $d_{i}=W_{i} / T$

$r_{i}$ : Point of reorder for product $i$

$u_{i}, v_{i}, \lambda_{i}$ : constants

$\mathcal{B}_{i}$ : as the constant of proportionality

$l_{i}$ : Length of period of production for product $i$

$p_{i}$ : Price of selling for product $i$ (per unit)

$c_{i}$ : Cost of unit production for product $i$ (per unit)

$\mu_{i}$ : Set up cost of production for product $i$ (per replenishment)

$x_{i}$ : Per unit per unit time cost of unit backlogging for product $i$.

$y_{i}$ : Per unit per unit time cost of unit carrying for product $i$.

$s_{i}$ : Per unit revenue of sales for product $i$.

$C 1_{i}$ : Per unit time cost of production for product $i$.

$C 2_{i}$ : Per unit time set up cost for product $i$.

$C 3_{i}$ : Per unit time backordering cost for product $i$.

$C 4_{i}$ : Per unit time holding cost for product $i$.

$T P_{i}\left(p_{i}, r_{i}, T\right)$ : Per unit time total profit for product $i$.

$\Omega\left(p^{*}, r^{*}, T\right)$ : Total profit for the whole inventory system

\subsection{Assumptions}

In the present study the following assumptions are summarized in whole study:

(1). Shortages are permitted and completely backordered.

(2). Infinite planning horizon.

(3). Inventory system with multi-products.

(4). Rate of demand is less than the rate of production for every product.

(5). The rate of production $P_{i}(t)$ is assumed as directly proportional to the rate of demand $W_{i}(t)$ for each product $i$ at time $\mathrm{t}\left(0 \leq t \leq l_{i}\right)$ and given as $P_{i}(t)=2_{i} W_{i}(t)$ with $2_{i}>1$.

(6). The rate of demand is time related which depletes with price in linear way with time and obeys a power 
pattern. Thus, the rate of demand can be assumed as follows:

$$
\begin{gathered}
W_{i}(t)=\left(u_{i}-v_{i}\right) \frac{\mu_{i}}{\lambda_{i}}(t / T)^{1 / \lambda_{i}-1},(0 \leq t \leq T) \text { where } 0 \\
<\lambda_{i}<\infty, \mathrm{u}_{i}>0, \mathrm{v}_{i}>0
\end{gathered}
$$

\section{Mathematical Modeling and Solution of the Problem}

In this study we consider a manufacturing industry which produces $N$ types of products. There is an average demand $d_{i}$ for each product and is related to time which depletes with price in linear way and obeys a power pattern. It is required to please the requirement of customers and also to optimize the overall profit at the same time. The pattern of inventory begins from s units of the total inventory at time $t=0$ and simultaneously the production starts at the initial time with rate of production $P_{i}(t)$ at time $t_{1 i}$ which goes to zero and proceeds until $t=l_{i}$ for each item $i$. In the same direction the replenishment quantity $W_{i}$ is produced. During the cycle $\left[0, l_{i}\right]$ the stock level of any product $i$ increasing with rate $P_{i}(t)-W_{i}(t)$. Later the stock level depletes up to $t=t_{2 i}$ as per demand. The demand will be backlogged during the interval $\left[t_{2 i}, T\right]$. Suppose $I_{1}(t)$ and $I_{2}(t)$ the levels of in hand inventory for any item $i$ in the intervals $\left[0, l_{i}\right]$ and $\left[l_{i}, t\right]$ respectively. In this study there are three decision variables (i) Price, (ii) Size of back order, and (iii). Scheduling period. The modeling of the present study is as follows:

The demand during the period $[0, \mathrm{~T}]$, which is a scheduling period is given as

$$
\int_{0}^{T} W_{i} d t=\int_{0}^{T}\left(u_{i}-v_{i} p_{i}\right) \frac{d_{i}}{\lambda_{i}}(t / T)^{1 / \lambda_{i}-1} d t=\left(u_{i}-\right.
$$

The whole system associated with this model can be given as follows.

$$
\begin{gathered}
\frac{\boldsymbol{d} \boldsymbol{I}_{\mathbf{1}}(\boldsymbol{t})}{\boldsymbol{d} \boldsymbol{t}}=\boldsymbol{P}_{\boldsymbol{i}}(\boldsymbol{t})-\boldsymbol{W}_{\boldsymbol{i}}(\boldsymbol{t})=\left(\boldsymbol{\beta}_{\boldsymbol{i}}-\mathbf{1}\right) \boldsymbol{W}_{\boldsymbol{i}}(\boldsymbol{t}) \\
=\left(\boldsymbol{\beta}_{\boldsymbol{i}}-\mathbf{1}\right)\left(\boldsymbol{u}_{\boldsymbol{i}}-\boldsymbol{v}_{\boldsymbol{i}} \boldsymbol{p}_{\boldsymbol{i}}\right) \frac{\boldsymbol{d}_{\boldsymbol{i}}}{\lambda_{\boldsymbol{i}}}(\boldsymbol{t} / \boldsymbol{T})^{\mathbf{1 / \lambda _ { i } - \mathbf { 1 }}} \\
I_{1}(0)=r_{i}, 0 \leq t \leq l_{i} \\
\frac{d I_{2}(t)}{d t}=-W_{i}(t)=-\left(u_{i}-v_{i} p_{i}\right) \frac{d_{i}}{\lambda_{i}}(t / T)^{1 / \lambda_{i}-1} \\
I_{2}(T)=r_{i}, l_{i} \leq t \leq T \quad I_{2}(T)=r_{i}, \mathrm{l}_{i} \leq t \leq T
\end{gathered}
$$

Using the boundary conditions $I_{1}(0)=I_{2}(T)=r_{i}$, the solution of equations (2) and (3) are given as

$$
\begin{array}{r}
I_{1}(t)=r_{i}+\left(\beta_{i}-1\right)\left(u_{i}-v_{i} p_{i}\right) d_{i} T(t / T)^{1 / \lambda_{i}}, 0 \leq t \leq l_{i} \\
I_{1}(t)=r_{i}+\left(\beta_{i}-1\right)\left(u_{i}-v_{i} p_{i}\right) d_{i} T(t / T)^{1 / \lambda_{i}}, \\
0 \leq t \leq l_{i} \\
I_{2}(t)=r_{i}+\left(u_{i}-v_{i} p_{i}\right) d_{i} T-\left(u_{i}-v_{i} p_{i}\right) d_{i} T(t / \\
T)^{1 / \lambda_{i}} \quad l_{i} \leq t \leq T
\end{array}
$$

A lot size production cycle is completed at $\mathrm{t}=l_{i}$. By solving equations (4) and (5), the level of maximum inventory can be determined, which is given as follows:

$$
\begin{gathered}
I_{i}=T / \beta_{\mathrm{i}}^{\lambda_{i}} \\
I_{\mathrm{i}}\left(l_{i}\right)=r_{i}+\frac{\beta_{i}-1}{\beta_{i}}\left(u_{i}-v_{i} p_{i}\right) d_{I} T
\end{gathered}
$$

The lot size $Q_{i}$ can be determined as follows,

$$
\begin{aligned}
Q_{0} \int_{0}^{l_{i}} P_{i}(t) d t=\int_{0}^{l_{i}} \beta_{i}\left(u_{i}-v_{i} p_{i}\right) \frac{d_{i}}{\lambda_{i}}(t / T)^{1 / \lambda_{i}-1} d t & =\left(u_{i}-v_{i} p_{i}\right) d_{i} T \\
= & \left(\mathrm{u}_{\mathrm{i}}-\mathrm{v}_{\mathrm{i}} \mathrm{p}_{\mathrm{i}}\right) \mathrm{d}_{\mathrm{i}} \mathrm{T}(8)
\end{aligned}
$$

As we had assumed that demand of period of scheduling is the same as lot quantity. So, it can be assumed that $I\left(l_{i}\right) \geq 0$ and $r_{i}>0$. Assume that at time $t=t_{1 i}$ the level of inventory goes to zero during the period of production. Using the condition $I_{1}\left(t_{1 i}\right)=0$ to find $t_{1 i}$ from equation (4), we have

$$
t_{1 i}=\left(\frac{-s_{i}}{\left(\beta_{i}-1\right)\left(u_{i}-v_{i} p_{i}\right) d_{i} T}\right)^{n} T
$$

Here $n$ is the number of cycles. The net level of inventory for the cycle $\left[l_{i}, T\right]$ goes to zero at time $t=t_{2 i}$. Using the condition $I_{2}\left(t_{2 i}\right)=0$ to find $t_{2 i}$ from equation (5), we have

$$
t_{2 i}=\left(1+\frac{s_{i}}{\left(u_{i}-v_{i} p_{i}\right) d_{i} T}\right)^{n} T
$$

Now, we calculate the four assumed costs for each product $i$ by considering the fact that the mean number of runs of production is $\frac{1}{T}$.

The revenue of sales for product $i$ is

$$
\mathrm{RS}_{\mathrm{i}}=\mathrm{p}_{\mathrm{i}} \frac{\mathrm{Q}_{\mathrm{i}}}{\mathrm{T}}=\left(\mathrm{u}_{\mathrm{i}}-\mathrm{v}_{\mathrm{i}} \mathrm{p}_{\mathrm{i}}\right) \mathrm{p}_{\mathrm{i}} \mathrm{d}_{\mathrm{i}}
$$

The cost of production for product $i$ is

$$
C 1_{i}=c_{i} \frac{Q_{i}}{T}=\left(u_{i}-v_{i} p_{i}\right) c_{i} d_{i}
$$

The set-up cost for product $i$ is

$$
\mathrm{C} 2_{\mathrm{i}}=\frac{\mu_{\mathrm{i}}}{\mathrm{T}}
$$

The Backordering or Shortage Cost

$$
\begin{aligned}
C 3_{i}= & \frac{-x_{i}}{T}\left[\int _ { 0 } ^ { t _ { 1 i } } \left\{r_{i}+\left(\beta_{i}-1\right)\left(u_{i}\right.\right.\right. \\
& \left.\left.-v_{i} p_{i}\right) d_{i} T(t / T)^{1 / \lambda_{i}}\right\} d t+\int_{t_{2 i}}^{T}\left\{r_{i}+\left(u_{i}\right.\right. \\
& \left.-v_{i} p_{i}\right) d_{i} T-\left(u_{i}\right. \\
& \left.\left.\left.-v_{i} p_{i}\right) d_{i} T(t / T)^{1 / \lambda_{i}}\right\} d t\right]
\end{aligned}
$$


On simplification, we have

$C 3_{i}=\left[\begin{array}{l}\frac{\left(r_{i}+\left(u_{i}-v_{i} p_{i}\right) d_{i} T\right)^{\lambda_{i}+1}}{\left(\lambda_{\mathrm{i}}+1\right)\left(u_{i}-v_{i} p_{i}\right)^{\lambda_{i}} d_{i}^{\lambda_{i}} T^{\lambda_{i}}}+ \\ \frac{\left(-r_{i}\right)^{\lambda_{i}+1}}{\left(\lambda_{i}+1\right)\left(\beta_{i}-1\right)^{\lambda_{i}}\left(u_{i}-v_{i} p_{i}\right)^{\lambda_{i}} d_{i}^{\lambda_{i}} T^{\lambda_{i}}}-\frac{\left(u_{i}-v_{i} p_{i}\right) d_{i} T}{\left(\lambda_{i}+1\right)}-r\end{array}\right] x_{i}$

The holding or carrying cost is

$C 4_{i}=\frac{y_{i}}{T}\left[\int_{t_{1 i}}^{l_{i}}\left\{r_{i}+\left(\beta_{i}-1\right)\left(u_{i}-v_{i} p_{i}\right) d_{i} T(t / T)^{1 / \lambda_{i}}\right\} d t\right.$
$\left.+\int_{l_{i}}^{t_{2 i}}\left\{r_{i}+\left(u_{i}-v_{i} p_{i}\right) d_{i} T-\left(u_{i}-v_{i} p_{i}\right) d_{i} T(t / T)^{1 / \lambda_{i}}\right\} d t\right]$

On integrating, we have

$$
\begin{gathered}
C 4_{i}==\left[\frac{\left(r_{i}+\left(u_{i}-v_{i} p_{i}\right) d_{i} T\right)^{\lambda_{i}+1}}{\left(\lambda_{i}+1\right)\left(u_{i}-v_{i} p_{i}\right)^{\lambda_{i}} d_{i}^{\lambda_{i}} T^{\lambda_{i}}}+\right. \\
\left.\frac{\left(-r_{i}\right)^{\lambda_{i}+1}}{\left(\lambda_{i}+1\right)\left(\beta_{i}-1\right)^{\lambda_{i}}\left(u_{i}-v_{i} p_{i}\right)^{\lambda_{i}} d_{i}^{\lambda_{i}} T^{\lambda_{i}}}-\frac{\left(u_{i}-v_{i} p_{i}\right) d_{i} T}{\left(\lambda_{i}+1\right)}\right] y_{i} \\
\left.-\frac{\left(u_{i}-v_{i} p_{i}\right) d_{\mathrm{i}} \mathrm{T}}{\left(? ?_{i}+1\right)}\right] y_{i}
\end{gathered}
$$

Now we can calculate the total profit for the product $i$ as follows:

$$
\begin{aligned}
& T P_{i}\left(p_{i}, r_{i}, T\right)=R S_{i}-C 1_{i}-C 2_{i}-C 3_{i}-C 4_{i} \\
& =\left(u_{i}-v_{i} p_{i}\right) p_{i} d_{i}-\frac{\left(r_{i}+\left(u_{i}-v_{i} p_{i}\right) d_{i} T\right)^{\lambda_{i}+1}\left(x_{i}+y_{i}\right)}{\left(\lambda_{i}+1\right)\left(u_{i}-v_{i} p_{i}\right)^{\lambda_{i}} d_{i}^{\lambda_{i}} T^{\lambda_{i}}}- \\
& \frac{\left(-r_{i}\right)^{\lambda_{i}+1}\left(x_{i}+y_{i}\right)}{\left(\lambda_{i}+1\right)\left(\beta_{i}-1\right)^{\lambda_{i}}\left(u_{i}-v_{i} p_{i}\right)^{\lambda_{i}} d_{i}^{\lambda_{i}} T^{\lambda_{i}}}+\frac{\left(u_{i}-v_{i} p_{i}\right) d_{i} T}{\left(\lambda_{i}+1\right)}\left(\frac{y_{i}}{\beta_{i}^{\lambda_{i}}}+\right. \\
& \left.x_{i}\right)-\frac{\mu_{i}}{T}-\left(u_{i}-v_{i} p_{i}\right) c_{i} d_{i}
\end{aligned}
$$

Now define the functions $\mathrm{p}^{*}=\left(\mathrm{p}_{1}, \mathrm{p}_{2}, \mathrm{p}_{3}, \ldots \ldots \mathrm{p}_{\mathrm{n}}\right)$, $r *=\left(r_{1}, r_{2}, r_{3}, \ldots . . r_{n}\right)$ and determine the total profit of inventory as follows:

$$
\Omega\left(p^{*}, r^{*}, T\right)=\sum_{i=1}^{N} T P_{i}\left(p_{i}, r_{i}, T\right)
$$

The essential conditions to optimize the total profit are as follows:

$$
\begin{aligned}
& \frac{\partial \Omega(p *, r * T)}{\partial r_{i}}=0, \frac{\partial \Omega(p *, r *, T)}{\partial T}=0 \text { and } \frac{\partial \Omega(p *, r *, T)}{\partial p_{i}}=0 \\
& \text { Using } \frac{\mathrm{a} ? ? ? ?\left(\mathrm{p}^{*}, \mathrm{r}^{*}, \mathrm{~T}\right)}{\mathrm{a} ? ? \mathrm{~T}}=0, \frac{\partial \Omega\left(p^{*}, r^{*}, T\right)}{\partial T}=0, \text { the optimal }
\end{aligned}
$$

length cycle which is given as

$$
T *=\sqrt{\frac{\sum_{i=1}^{N} \mu_{i}}{\sum_{i=1}^{N}\left[\left(\frac{\left(u_{i}-v_{i} p_{i}\right) d_{i}}{\left(\lambda_{i}+1\right)}\right)\left(\begin{array}{l}
\left(x_{i}+y_{i}\right)\left(1-z_{i}\right)^{\lambda_{i}} \\
+\lambda_{i} x_{i} z_{i} *-\left(\frac{y_{i}}{\beta_{i} \lambda_{i}}+x_{i}\right)
\end{array}\right)\right]}}
$$

where $z_{i}$ is a new variable defined as

$$
\mathrm{z}_{\mathrm{i}}=\frac{-\mathrm{r}_{\mathrm{i}}}{\left(\mathrm{u}_{\mathrm{i}}-\mathrm{v}_{\mathrm{i}} \mathrm{p}_{\mathrm{i}}\right) \mathrm{d}_{\mathrm{i}} \mathrm{T}} \text {, and }\left(1-z_{i}\right)^{\lambda_{i}}-\frac{z_{i}^{\lambda_{i}}}{\left(\beta_{i}-1\right)^{\lambda_{i}}}-\frac{x_{i}}{\left(x_{i}+y_{i}\right)}=0
$$

Also, the optimal lot quantity $\left(\mathrm{r}_{\mathrm{i}}{ }^{*}\right)$ and the optimal re-order point $\left(Q_{i} * \mathrm{Q}_{\mathrm{i}}{ }^{*}\right)$ are given as follows:

$$
\begin{aligned}
& r_{i}^{*}=-z_{i}^{*}\left(u_{i}-v_{i} p_{i}\right) d_{i} T^{*} \\
& Q_{i}^{*}=\left(u_{i}-v_{i} p_{i}\right) d_{i} T^{*}
\end{aligned}
$$

Now the condition to optimize the TPF (total profit function)

$$
\text { i.e., } \Omega\left(\vec{p}, \vec{r}^{*}, T^{*}\right) \text { for any } r_{1}^{*}, r_{2}^{*}, \ldots, r_{N}^{*}, T^{*} \text { is }
$$

given as

$$
\begin{aligned}
& \frac{\partial \Omega\left(\vec{p}, \vec{r}^{*}, T^{*}\right)}{\partial p_{i}}=-u_{i} d_{i}-2 v_{i} p_{i} d_{i}+v_{i} c_{i} d_{i} \\
& -\frac{v_{i} d_{i} T^{*}}{\left(\lambda_{i}+1\right)}\left(\frac{y_{i}}{\beta_{i}^{\lambda_{i}}}+x_{i}\right)\left(x_{i}+y_{i}\right) \frac{v_{i}}{\left(\lambda_{i}+1\right) d_{i}^{\lambda_{i}} T^{* \lambda_{i}}} \\
& {\left[\frac{\left(r_{i}\left(u_{i}-v_{i} p_{i}\right) d_{i} T^{*}\right)^{\lambda_{i}}\left(\left(u_{i}-v_{i} p_{i}\right) d_{i} T^{*}-\lambda_{i} r_{i}\right)}{\left(u_{i}-v_{i} p_{i}\right)^{\lambda_{i}+1}}-\frac{\lambda_{i}\left(-r_{i}^{*}\right)^{\lambda_{i}+1}}{\left(\beta_{i}-1\right)^{\lambda_{i}}\left(u_{i}-v_{i} p_{i}\right)^{\lambda_{i}+1}}\right]}
\end{aligned}
$$

\section{Process of Finding the Optimal Values}

It is difficult to solve the equation (23) as it is complex and time consuming also. So, an alternate process is used to obtain the optimal values of $\vec{p}, \vec{r}, T * T^{*} \vec{p}, \vec{r}$, Tand $\Omega$.

Step 1: For every item $i, p_{i}=c_{i}$, where $c_{i}<\frac{u_{i}}{v_{i}}$.

If $T * T^{*} \geq 0$

i.e., $\frac{\sum_{i=1}^{N} \mu_{i}}{\sum_{i=1}^{N}\left[\left(\frac{\left(u_{i}-v_{i} p_{i}\right) d_{i}}{\left(\lambda_{i}+1\right)}\right)\left(\left(x_{i}+y_{i}\right)\left(1-z_{i}{ }^{*}\right)^{\lambda_{i}}+\lambda_{i} x_{i} z_{i}{ }^{*}-\left(\frac{y_{i}}{\beta_{i}^{\lambda_{i}}}+x_{i}\right)\right)\right]} \geq 0$

determine $\mathrm{T}^{*}$ and then find out $\vec{r}$ *and $\Omega\left(\vec{p}, \vec{r}^{*}, T^{*}\right)$, otherwise there is no required solution.

Step 2: For every item $i(i=1,2, \ldots N)$, it is assumed that $p_{i}=p_{i}+e$ and $p_{j}=p_{j}$ for each $i \neq j$. Then determine best economic period of scheduling $\left(\vec{r}_{i}^{*}, T_{i}{ }^{*}\right)$ (say) and the function of total profit $\Omega_{i}\left(\vec{p}, \vec{r}_{i}^{*}, T_{i}^{*}\right)$ say).

Step 3: Select the item $\mathrm{k}$ with the following conditions a). It is possible to determine $T_{k} *$.

$$
\begin{array}{ll}
\text { b). } & p_{k}<\frac{u_{k}}{v_{k}} \mathrm{p}_{\mathrm{k}}<\frac{\mathrm{u}_{\mathrm{k}}}{\mathrm{v}_{\mathrm{k}}} \\
\text { c). } & \Omega_{k}\left(\vec{p}, \vec{r}_{k}^{*}, T_{k}^{*}\right)>\Omega\left(\vec{p}, \vec{r}^{*}, T^{*}\right) \text { and } \\
& \Omega_{k}\left(\vec{p}, \vec{r}_{k}^{*}, T_{k}^{*}\right)>\Omega_{j}\left(\vec{p}, \vec{r}_{j}^{*}, T_{j}^{*}\right) \text { for each } j \neq k .
\end{array}
$$

If these conditions work properly then the best solutions are $\overrightarrow{\mathrm{r}}^{*}, \mathrm{~T}^{*}, \Omega\left(\overrightarrow{\mathrm{p}}, \overrightarrow{\mathrm{r}}^{*}, \mathrm{~T}^{*}\right)$ and reach to the step 5 .

Step 4: If $p_{k}=p_{k}+e$ and $p_{j}=p_{j}$ for each $j \neq k$ then $T *=T_{k} *$ and $\Omega(\vec{p}, \vec{r} *, T *)=\Omega_{k}\left(\vec{p}, \vec{r}_{k} *, T_{k} *\right)$, thus 
we return to the step 2 .

Step 5: End.

\section{Numerical Verification of the Study}

Here the present study is verified by a numerical example.

Taking an inventory model for a unique item with the following input values of the parameters as:

$$
\mu=102, x=4.8, y=4.2, d=1180, u=106,
$$

$v=2, c=11, \beta=1.5$, and the power pattern index $\lambda=3$.
The results with these parameters are as follows:

$$
\begin{aligned}
& z^{*}=0.16542, \mathrm{~T}^{*}=0.7435, \mathrm{Q}^{*}=3372.5, \\
& \mathrm{r}^{*}=-568.215, \mathrm{p}^{*}=29, \text { and } T P *=949845 .
\end{aligned}
$$

* Optimal schemes of the present model considering many combinations of the parameters $\beta$ and $c$ are presented in Table1.

*Optimal schemes of the present model considering many combinations of the parameters $\lambda$ and $c$ presented in Table 2.

*Optimal schemes of the present model considering the

\begin{tabular}{|c|c|c|c|c|c|c|c|}
\hline $\begin{array}{c}\text { Rate of } \\
\text { production }\end{array}$ & $\begin{array}{c}\text { Cost of } \\
\text { production }\end{array}$ & $Z^{*}$ & $\mathrm{~T}^{*}$ & $\mathrm{r}^{*}$ & $\mathrm{Q}^{*}$ & $\mathrm{p}^{*}$ & $\Omega^{*}$ \\
\hline \multirow{5}{*}{$\beta=1.2$} & $\mathrm{C}=12$ & \multirow{5}{*}{0.065324} & 0.1602 & -475.7654 & 7271.4 & 30 & 957430 \\
\hline & $C=16$ & & 0.1765 & -452.8765 & 6674.2 & 34 & 755674 \\
\hline & $C=20$ & & 0.1834 & -418.6373 & 6245.5 & 36 & 545262 \\
\hline & $C=24$ & & 0.1940 & -378.8675 & 5688.2 & 38 & 395423 \\
\hline & $C=28$ & & 0.2542 & -365.7654 & 5188.1 & 40 & 251674 \\
\hline \multirow{5}{*}{$\beta=1.4$} & $\mathrm{C}=12$ & \multirow{5}{*}{0.143562} & 0.0932 & -578.8758 & 4274.2 & 30 & 947430 \\
\hline & $C=16$ & & 0.0985 & -562.6277 & 3986.3 & 34 & 745674 \\
\hline & $C=20$ & & 0.1123 & -512.6546 & 3693.2 & 36 & 542677 \\
\hline & $C=24$ & & 0.1176 & -478.8075 & 3286.6 & 38 & 385423 \\
\hline & $C=28$ & & 0.1256 & -437.8754 & 2784.6 & 40 & 241674 \\
\hline \multirow{5}{*}{$\beta=1.6$} & $C=12$ & \multirow{5}{*}{0.163865} & 0.0712 & -582.4562 & 3486.3 & 30 & 942654 \\
\hline & $C=16$ & & 0.0784 & -534.6578 & 3024.5 & 34 & 742897 \\
\hline & $C=20$ & & 0.0832 & -485.7688 & 2865.6 & 36 & 537654 \\
\hline & $C=24$ & & 0.0965 & -446.7634 & 2576.8 & 38 & 378964 \\
\hline & $C=28$ & & 0.1426 & -4234.765 & 2254.8 & 40 & 237644 \\
\hline \multirow{5}{*}{$\beta=1.8$} & $C=12$ & \multirow{5}{*}{0.180544} & 0.0675 & -564.7654 & 3215.4 & 30 & 937430 \\
\hline & $C=16$ & & 0.0712 & -512.8727 & 2856.2 & 34 & 735674 \\
\hline & $C=20$ & & 0.0782 & -475.3772 & 2675.8 & 36 & 532677 \\
\hline & $C=24$ & & 0.0864 & -421.6543 & 2365.4 & 38 & 375423 \\
\hline & $C=28$ & & 0.0975 & & 2163.6 & 40 & 241674 \\
\hline \multirow{5}{*}{$\beta=2.0$} & $C=12$ & \multirow{5}{*}{0.182345} & 0.0642 & -543.8764 & 2898.0 & 30 & 927430 \\
\hline & $C=16$ & & 0.0674 & -498.8756 & 2765.8 & 34 & 725674 \\
\hline & $C=20$ & & 0.0732 & -470.6543 & 2610.5 & 36 & 512677 \\
\hline & $C=24$ & & 0.0812 & -410.2345 & 2286.0 & 38 & 367423 \\
\hline & $C=28$ & & 0.0876 & -385.3565 & 2046.6 & 40 & 232474 \\
\hline
\end{tabular}
distinct value of $u$ presented in Table 3 .

Table 1. Optimal schemes of the present model considering many combinations of the parameters $\beta$ and $c$.

Table 2. Optimal schemes of the present model considering many combinations of the parameters $\lambda$ and $c$

\begin{tabular}{|c|c|c|c|c|c|c|c|}
\hline $\begin{array}{c}\text { Rate of } \\
\text { production }\end{array}$ & $\begin{array}{c}\text { Cost of } \\
\text { production }\end{array}$ & $z^{*}$ & $\mathrm{~T}^{*}$ & $\mathrm{r}^{*}$ & $\mathrm{Q}^{*}$ & $\mathrm{p}^{*}$ & $\Omega^{*}$ \\
\hline \multirow{2}{*}{$\lambda=0.6$} & $c=15$ & \multirow{2}{*}{0.096542} & 0.0745 & -310.542 & 3486.3 & 35 & 967415 \\
& $c=25$ & 0.0834 & -287.234 & 3024.5 & 40 & 543276 \\
\hline \multirow{2}{*}{$\lambda=1.5$} & $c=15$ & \multirow{2}{*}{0.176542} & 0.0756 & -576.345 & 3565.6 & 35 & 967425 \\
& $c=25$ & 0.0854 & -498.456 & 2576.8 & 40 & 543286 \\
\hline \multirow{2}{*}{$\lambda=2.5$} & $c=15$ & \multirow{2}{*}{0.187642} & 0.0768 & -724.865 & 3698.6 & 35 & 967445 \\
& $c=25$ & 0.0878 & -645.342 & 3286.0 & 40 & 543290 \\
\hline \multirow{2}{*}{$\lambda=3.5$} & $c=15$ & \multirow{2}{*}{0.176554} & 0.0785 & -590.342 & 3576.6 & 35 & 967455 \\
& $c=25$ & & 0.0886 & -512.452 & 3065.8 & 40 & 543298 \\
\hline
\end{tabular}

Table 3. Optimal schemes of the present model considering the distinct value of $u$.

\begin{tabular}{|c|c|c|c|c|c|c|}
\hline$u$ & $z^{*}$ & $\mathrm{~T}^{*}$ & $\mathrm{r}^{*}$ & $\mathrm{Q}^{*}$ & $\mathrm{p}^{*}$ & $\Omega^{*}$ \\
\cline { 1 - 5 } & \multirow{3}{*}{0.187342} & 0.0744 & -554.123 & 3217.2 & 32 & 968072 \\
\cline { 1 - 5 } 210 & & 0.0456 & -865.345 & 4849.5 & 32 & 4966724 \\
\cline { 3 - 7 } 310 & & 0.0385 & -1123.24 & 6028.2 & 32 & 11965000 \\
\hline
\end{tabular}




\section{Conclusions and Future Scope}

In the present study an inventory policy in a manufacturing system with time varying power pattern demand is presented. It is assumed that the rate of production varies with the rate of demand and the requirement of customers is bounded by price linearity. Multiple items are considered in the system of inventory. The shortages are permitted and completely backordered. Optimization methods are used to obtain the maximum profit and numerical verification is presented to illustrate the study. If the rate of production is a fixed parameter than an increment in unit production cost results decrement of total profit as well as economic lot whereas there is an increment in the optimal price and optimal length of inventory cycle. Similarly, if the powers demand index is fixed then an increment in unit production cost results a decrement in total profit as well as economic lot whereas the optimal price and optimal length of inventory cycle increase. It is also observed that the increment in rate of production results a slight decrement in total profit and decrement in both optimal lot size and scheduling period.

The present study can be extended by using it for obtaining products and shortages with partial backorder in an inventory system.

\section{Acknowledgements}

We are very grateful to experts for their appropriate and constructive suggestions to improve this manuscript.

\section{REFERENCES}

[1] L.C. Barbosa, M. Friedman. Deterministic inventory lot size models-A general root law, Management Science, Vol. 24, No. 8, 819-826, 1978.

[2] E.A. Silver, R. Peterson. Decision Systems for Inventory Management and Production Planning: Solutions Manual. 2nd Edn., John Wiley and Sons Australia, Limited, ISBN-10: 0471818143, 493, 1985.

[3] A. Mitra, J.F. Cox, R.R. Jesse Jr. A note on determining order quantities with a linear trend in demand, The Journal of the Operational Research Society, Vol. 35, No. 2, 141-144, 1984.

[4] R.C. Baker, T.L. Urban. A deterministic inventory system with an inventory-level-dependent demand rate. J. Operat. Res. Soc., Vol. 39: 823-831, 1988.

[5] B.N. Mandal, S. Phaujda. An inventory model for deteriorating items and stock-dependent demand rate. J. Operat. Res. Soc., Vol. 39, 823-831, 1989.

[6] B. Sarkar, P. Mandal, S. Sarkar. An EMQ model with price and time dependent demand under the effect of reliability and inflation, Applied Mathematics and Computation, Vol. 231, 414-421, 2014.

[7] T.L. Urban. Inventory models with the demand rate dependent on stock and shortage levels, Int. J. Product. Economic. Vol. 40, 21-28. 1995.

[8] H.K. Alfares. Inventory model with stock-level dependent demand rate and variable holding cost, Int. J. Product. Economic. Vol. 108, 259-265, 2007.

[9] T.K. Datta, and A.K. Pal. A note on an inventory model with inventory-level-dependent demand rate. J. Oper. Res. Soc., Vol. 41, 971-975, 1990.

[10] W.C. Lee, J.W. Wu. An EOQ model for items with Weibull distributed deterioration, shortages and power demand pattern, international Journal of information and Management Sciences, Vol-13, No.2, 19-34, 2002.

[11] T. J. Singh, S.R. Singh, R. Dutt. An EOQ model for perishable items with power demand and partial backlogging, International Journal of Production Economics, Vol. 15, No. 1, 65-72, 2009.

[12] S. Pal, A. Goswami, K.S. Chaudhuri, A deterministic inventory model for deteriorating items with stock-dependent demand rate. Int. J. Product. Econom. Vol. 32, 291-299, 1993.

[13] H. Hwang, K.H. Hahn. An optimal procurement policy for items with an inventory level-dependent demand rate and fixed lifetime. Eur. J. Operat. Res., Vol. 127, 537-545, 2000.

[14] S.S. Mishra., P.K. Singh. Partial backlogging EOQ model for queued customers with power demand and quadratic deterioration, computational approach, American Journal of Operation Research, Vol.3, No.2, 13-27, 2013.

[15] J. Sicilia, M. González-De-la-Rosa, J. Febles-Acosta, D. Alcaide-López-de-Pablo. Optimal policy for an inventory system with power demand, backlogged shortages and production rate proportional to demand rate, International Journal of Production Economics, Vol. 155, 163-171, 2014.

[16] R.P. Tripathi, S. Pareek, M. Kaur, Inventory models with power demand and inventory-induced demand with holding cost functions, American Journal of Applied Sciences, Vol. 14, No. 6, 607-613, 2017.

[17] J. Ray, K.S. Chaudhuri. An EOQ model with stock-dependent demand, shortage, inflation and time discounting. In. J. Product. Economic, Vol. 53, 171-180, 1997.

[18] B.C. Giri, A. Goswami, K.S. Chaudhuri An EOQ model for deteriorating items with time varying demand and costs. J. Oper. Res., Vol. 47, 1398-1405, 1996.

[19] S. Banerjee, A. Sharma, Optimal procurement and pricing policies for inventory models with price and time dependent seasonal demand, Mathematical and Computer Modelling, Vol. 51, No. 5-6, 700-714, 2010.

[20] A. Banerjee. A joint economic-lot-size model for purchaser and vendor. Decis. Sci., Vol. 17, 292-311, 1986.

[21] S.K. Goyal, A Joint economic-lot-size model for purchaser and vendor: A comment. Decis. Sci., Vol. 19, 236-241, 1988. 
[22] G. Liu, J. Zhang W. Teng, Joint dynamic pricing and investment strategy for perishable foods with price quantity dependent demand, Annals of Operations Research, Vol.226, 913-929, 2005.

[23] R.M. Hill, On optimal two-stage lot sizing and inventory batching policies. Int. J. Product. Econom. Vol. 66, 149-158. 2000.

[24] S.X. Zhu. Dynamic replacement, production and pricing decisions in the face of supply disruption and random price-sensitive demand, International Journal of Production Economics, Vol.146, No.2, 612-619, 2013.

[25] J.T. Teng, I.P. Krommyada, K. Skouri, K.R. Lou A comprehensive extension of optimal ordering policy for stock-dependent demand under progressive payment scheme. Eur. J. Operat. Res., Vol. 215, 97-104, 2011.

[26] S.K. Goyal, C.T. Chang. Optimal ordering and transfer policy for an inventory with stock dependent demand. Eur. J. Operat. Res., Vol. 1996, 177-185, 2009.

[27] P.C. Yang, H.M. Wee. An integrated multi- lot-size production inventory model for deteriorating item. Comput. Operat. Res., Vol. 30, 671-682, 2003.

[28] M.R. Gholamian, M. Heydari. An inventory model with METRIC approach in location-routing-inventory problem, Advances in Production Engineering \& Management, Vol. 12, No. 2, 115-126, 2017.

[29] Y. Chiu, S.P., Kuo, J.S. Chiu, S.W., Y.T. Hsieh. Effect of delayed differentiation on a multiproduct vendor- buyer integrated inventory system with rework, Advances in Production Engineering \& Management, Vol. 11, No. 4, 2016.

[30] S. Tiwari, W. Ahmed, B. Sarkar Sustainable ordering policies for non-instantaneous deteriorating items under carbon emission and multi-trade-credit-policies, Journal of Cleaner Production, (SCIE), Vol. 240, 118 - 183. 2019.

[31] M. Kumar, A. Chauhan, S.J. Singh, M. Sahni, An Inventory Model on Preservation Technology with Trade Credits under Demand Rate Dependent on Advertisement, Time and Selling Price, Universal Journal of Accounting and Finance, Vol. 8, No. 3, 65-74, 2020. 